OPEN ACCESS

Edited by:

Wen-Jun Li,

Sun Yat-sen University, China

Reviewed by:

Shawn Chen

Revive Genomics Inc., USA

Jiangxin Wang,

Shenzhen University, China

*Correspondence:

Eung-Soo Kim

eungsoo@inha.ac.kr

Specialty section:

This article was submitted to Microbiotechnology, Ecotoxicology

and Bioremediation,

a section of the journal

Frontiers in Microbiology

Received: 31 December 2016

Accepted: 24 February 2017

Published: 15 March 2017

Citation:

Nah H-J, Pyeon H-R, Kang S-H, Choi S-S and Kim E-S (2017) Cloning and Heterologous Expression of a Large-sized Natural Product

Biosynthetic Gene Cluster in

Streptomyces Species

Front. Microbiol. 8:394.

doi: 10.3389/fmich.2017.00394

\section{Cloning and Heterologous Expression of a Large-sized Natural Product Biosynthetic Gene Cluster in Streptomyces Species}

\author{
Hee-Ju Nah, Hye-Rim Pyeon, Seung-Hoon Kang, Si-Sun Choi and Eung-Soo Kim * \\ Department of Biological Engineering, Inha University, Incheon, South Korea
}

Actinomycetes family including Streptomyces species have been a major source for the discovery of novel natural products (NPS) in the last several decades thanks to their structural novelty, diversity and complexity. Moreover, recent genome mining approach has provided an attractive tool to screen potentially valuable NP biosynthetic gene clusters (BGCs) present in the actinomycetes genomes. Since many of these NP BGCs are silent or cryptic in the original actinomycetes, various techniques have been employed to activate these NP BGCs. Heterologous expression of BGCs has become a useful strategy to produce, reactivate, improve, and modify the pathways of NPs present at minute quantities in the original actinomycetes isolates. However, cloning and efficient overexpression of an entire NP BGC, often as large as over $100 \mathrm{~kb}$, remain challenging due to the ineffectiveness of current genetic systems in manipulating large NP BGCs. This mini review describes examples of actinomycetes NP production through BGC heterologous expression systems as well as recent strategies specialized for the large-sized NP BGCs in Streptomyces heterologous hosts.

Keywords: Streptomyces, natural product, biosynthetic gene cluster, heterologous expression, large-sized

\section{INTRODUCTION}

Natural products (NPs) and their derivatives lead a huge pharmaceutical market share comprising $61 \%$ of anticancer drugs and $49 \%$ of anti-infection medicine in the past 30 years (Newman and Cragg, 2012). Especially, actinomycetes NPs are a major resource for drug discovery and development, mainly due to their structural novelty, diversity, and complexity (Donadio et al., 2007). Isolation and characterization of NP biosynthetic gene clusters (BGCs) have further accelerated our understanding of their molecular biosynthetic mechanisms, leading to the rational redesign of novel NPs through BGC manipulation (Fischer et al., 2003; Castro et al., 2015).

Some of these potentially valuable BGCs are, however, derived from non-culturable metagenomes or genetically recalcitrant microorganisms. Moreover, many of these BGCs are expressed poorly or not at all under laboratory culture conditions, which makes it challenging to characterize the target NPs (Galm and Shen, 2006). Since efficient expression of actinomycetes NP BGCs present a major bottleneck for novel NP discovery, various cryptic BGC awakening strategies such as regulatory genes control, ribosome engineering, co-culture fermentation, and heterologous expression have been pursued for NP development (Tang et al., 2000; Flinspach et al., 2014; Martinez-Burgo et al., 2014; Miyamoto et al., 2014). 
A traditional method for BGC cloning involves cosmid library construction by partial digestion or random shearing of chromosomal DNA. A typical size of NP BGC is usually larger than $20 \mathrm{~kb}$ (sometimes over $100 \mathrm{~kb}$ ), and a cosmid vector system can only accept a relatively small BGC (up to $40 \mathrm{~kb}$ ) or only a part of a large BGC. Therefore, cloning and efficient overexpression of an entire BGC still remains challenging due to the ineffectiveness of current host cells including the genetic and metabolic characteristics in manipulating large BGCs for heterologous expression. This mini review summarizes the list of the actinomycetes NP BGCs that have been successfully cloned and expressed in Streptomyces heterologous hosts (Table 1). In addition, three cloning and heterologous expression systems, which are quite suitable for large NP BGCs, such as transformation-associated recombination (TAR) system, integrase-mediated recombination (IR) system, and plasmid Streptomyces bacterial artificial chromosome (pSBAC) system are introduced (Figure 1).

\section{TRADITIONAL METHOD FOR HETEROLOGOUS EXPRESSION OF NP BGCS}

We summarized about 90 actinomycetes NP BGCs that have been successfully expressed in Streptomyces heterologous hosts from the last several decades (Table 1). Relatively small BGCs encoding Type II polyketide were first to be isolated at the beginning of heterologous expression research. Many of the listed BGCs (about 83\%) were isolated by cosmid/fosmid library construction and some of these BGCs were cloned into replicative or integrative vector by linear-plus-linear (recombination between two linear DNAs) or linear-plus-circular (recombination between linear and replicating circular DNA) homologous recombination. Approximately $60 \%$ of BGCs were integrated into the heterologous host chromosome and only $37 \%$ of BGCs existed in the heterologous host via replicative plasmid. Cosmid vectors such as pOJ446 and SuperCos1 were used to be replicative or integrative in the heterologous host, so the production level of the heterologously expressed NP BGC varied significantly. Some BGCs were isolated with two different vector systems, followed by heterologous expression via both integrative and replicative systems. For example, the epothilone BGC was expressed by both pSET152-based integration vector and SCP2*-based replication vectors, so that its expression level was increased from $0.1 \mathrm{mg} / \mathrm{L}$ in the original Sorangium cellulosum system to $20 \mathrm{mg} / \mathrm{L}$ in the epothilone BGC-expressing Streptomyces host (Tang et al., 2000). S. coelicolor and S. lividans were two major strains for heterologous expression, thanks to their well-characterized genetic and biochemical properties. About 12\% BGCs were expressed in another popular heterologous host, $S$. albus, which has fast growth and an efficient genetic system (Zaburannyi et al., 2014). Comparing with the original NP producing strains, approximately $14 \%$ of NPs had a higher expression level and 12\% lower when they were expressed in the heterologous hosts. When bernimamycin BGC was heterologously expressed both in S. lividans and $S$. venezuelae, its production yield was increased 2.4 -fold in $S$. lividans with no production in S. venezuelae (Malcolmson et al., 2013).

\section{CLONING SYSTEMS OF LARGE NP BGCS FOR HETEROLOGOUS EXPRESSION IN STREPTOMYCES}

\section{TAR System}

The TAR system takes advantage of the natural in vivo homologous recombination of Saccharomyces cerevisiae (Larionov et al., 1994). It has also been applied to capture and express large biosynthetic gene clusters from environmental DNA samples (Feng et al., 2010; Kim et al., 2010). Yamanaka and colleagues designed TAR cloning vector, pCAP01, which consists of three elements, one from each of yeast, E. coli, and actinobacteria (Yamanaka et al., 2014). The target BGC can be directly captured and manipulated in yeast background, and the captured BGC can be shuttled between E. coli and actinobacteria species. It also has a pUC ori that could stably carry an over $50 \mathrm{~kb}$ insert in E. coli hosts. The pCAP01 vector contains oriT and attP-int that can transfer the target BGC by conjugation, and the DNA stability can be maintained by insertion into heterologous host chromosomes. To generate a capturing vector, both flanking homologous arms of the target BGC were PCRamplified and cloned into the pCAP01. The linearized capturing vector and the restriction enzyme digested genomic DNA were co-transformed into yeast, then the target BGC was captured by yeast recombination activities (Figure 1A). The marinopyrrole BGC $(30 \mathrm{~kb})$ and the taromycin A BGC $(67 \mathrm{~kb})$ were captured by this TAR system, and functionally expressed in Streptomyces coelicolor (Yamanaka et al., 2014).

\section{IR System}

Most cloning systems to clone a large DNA fragment directly from bacterial genome are based on different site-specific recombination systems that consist of a specialized recombinase and its target sites. The IR system is based on ФBT1 integrase-mediated site-specific recombination and simultaneous Streptomyces genome engineering (Du et al., 2015). The actinorhodin BGC, the napsamycin BGC and the daptomycin BGC were successfully isolated by the IR system (Du et al., 2015). pUC119-based suicide vector and pKC1139 carrying mutated attP or attB, respectively, and an integrative plasmid containing the $\Phi B T 1$ integrase gene were used for the system (Figure 1B). The pUC119-based plasmid carrying mutated attB and a homologous region to $5^{\prime}$ end of the target BGC was introduced into the chromosome by single crossover. The pKC1139 carrying mutated attP and a homologous region to $3^{\prime}$ end of the BGC was transferred and integrated into chromosome by conjugation and single crossover through cultivation at high temperature above $34^{\circ} \mathrm{C}$. Expression of $\Phi B T 1$ integrase leads to excision of the pKC1139 containing the target BGC. The pKC1139 containing BGC from original producing Streptomyces was extracted and transferred into E. coli for recovery. The IR system was only expressed in parental strain not heterologous 


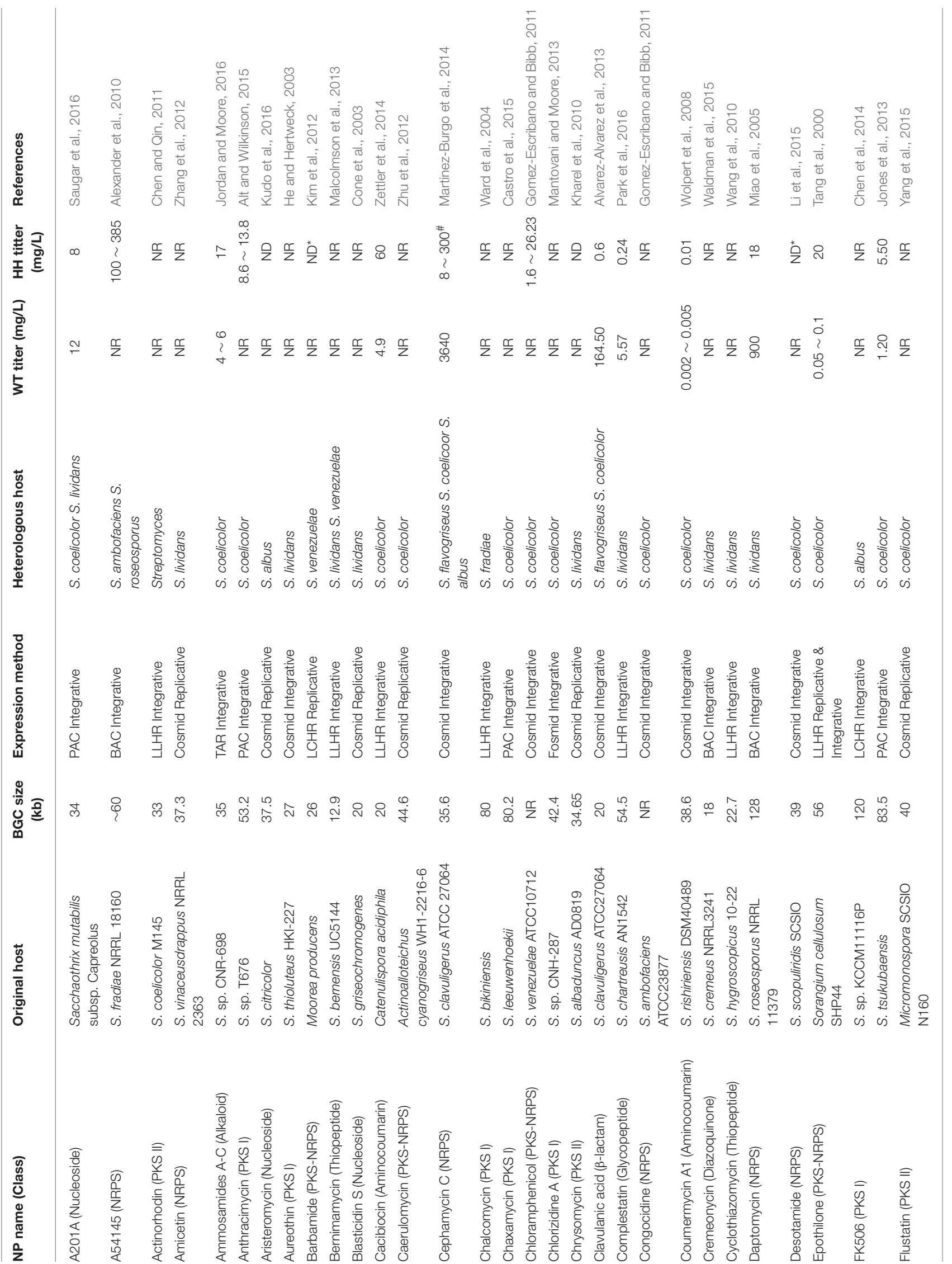




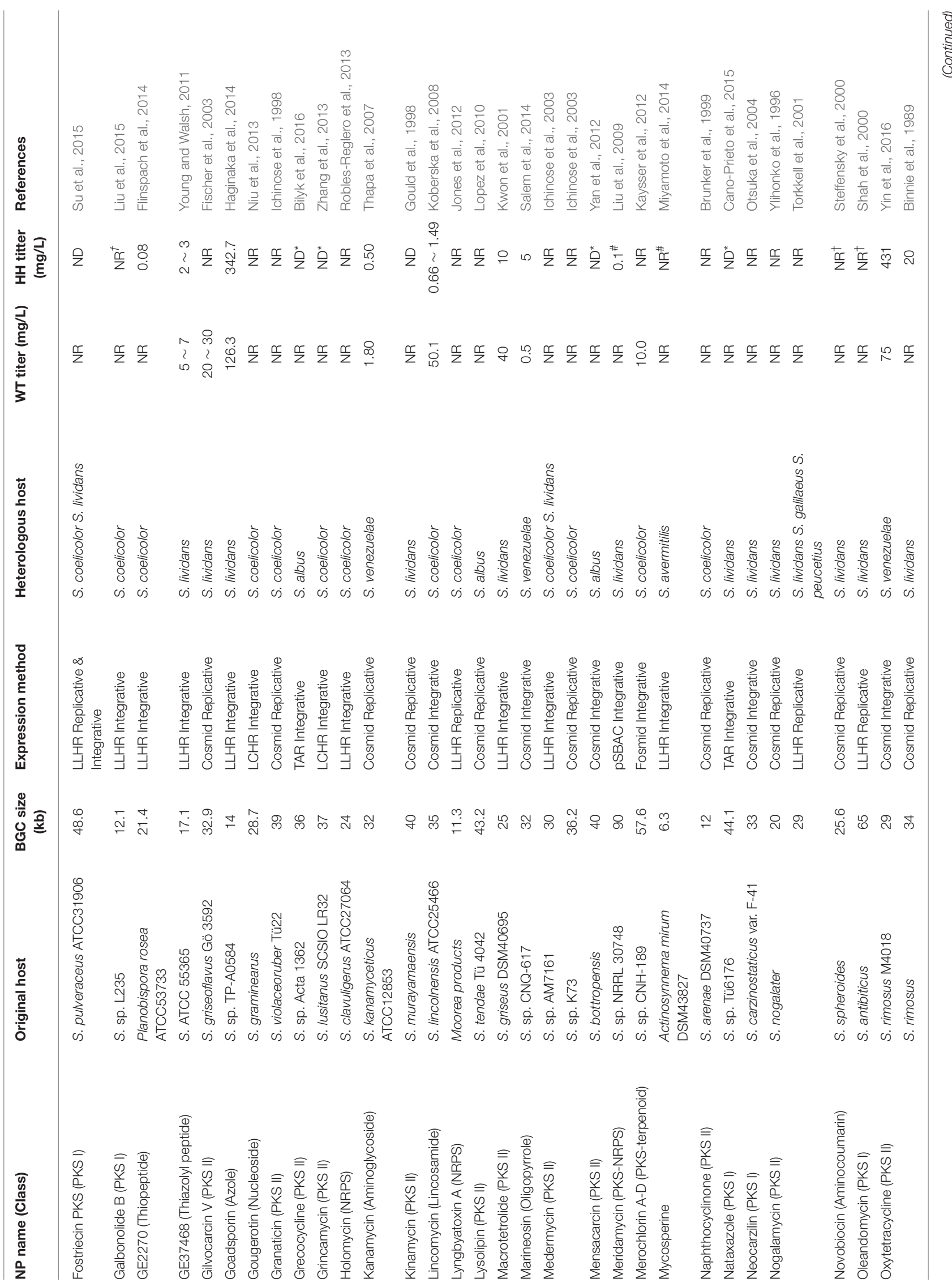




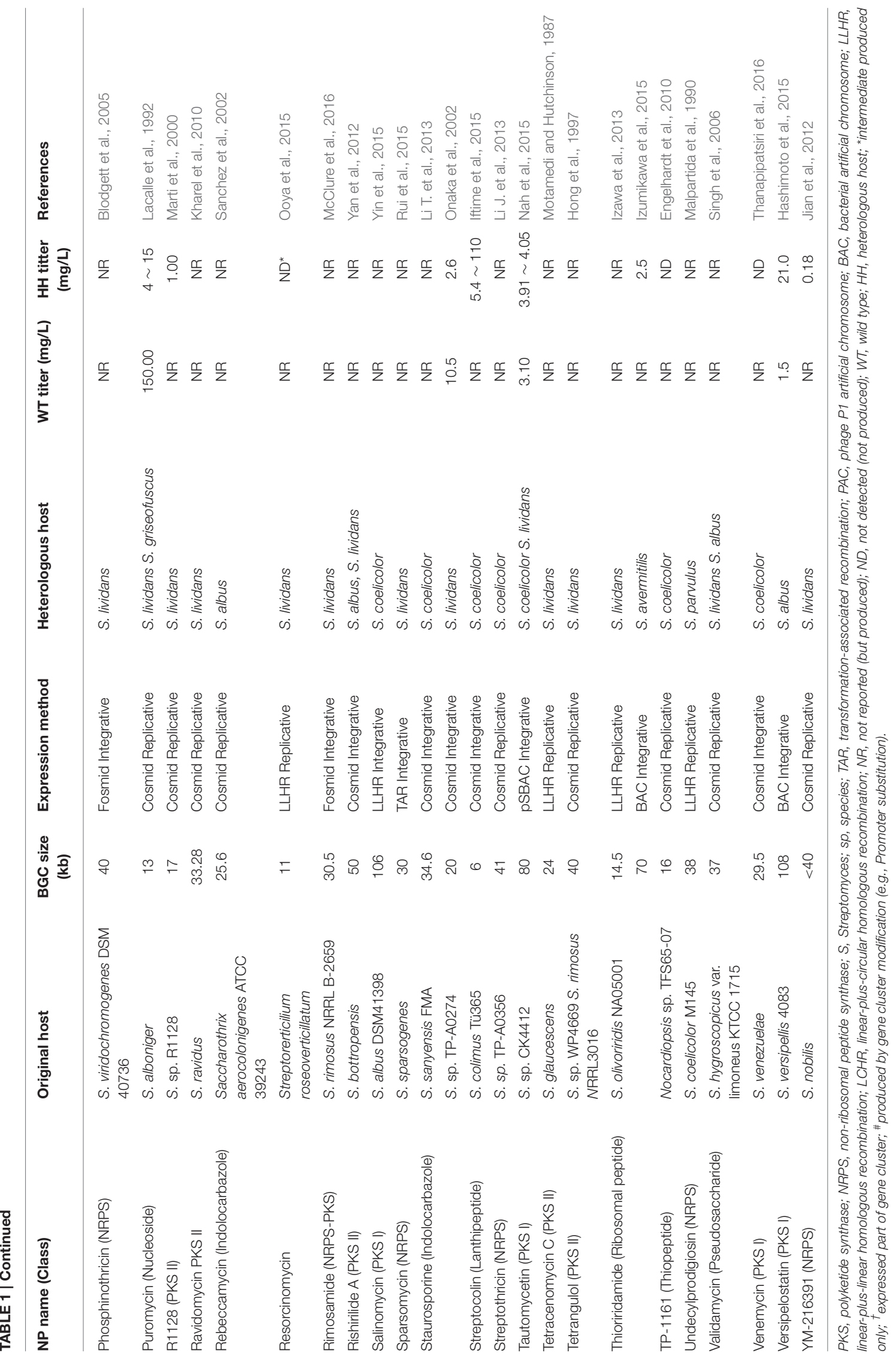




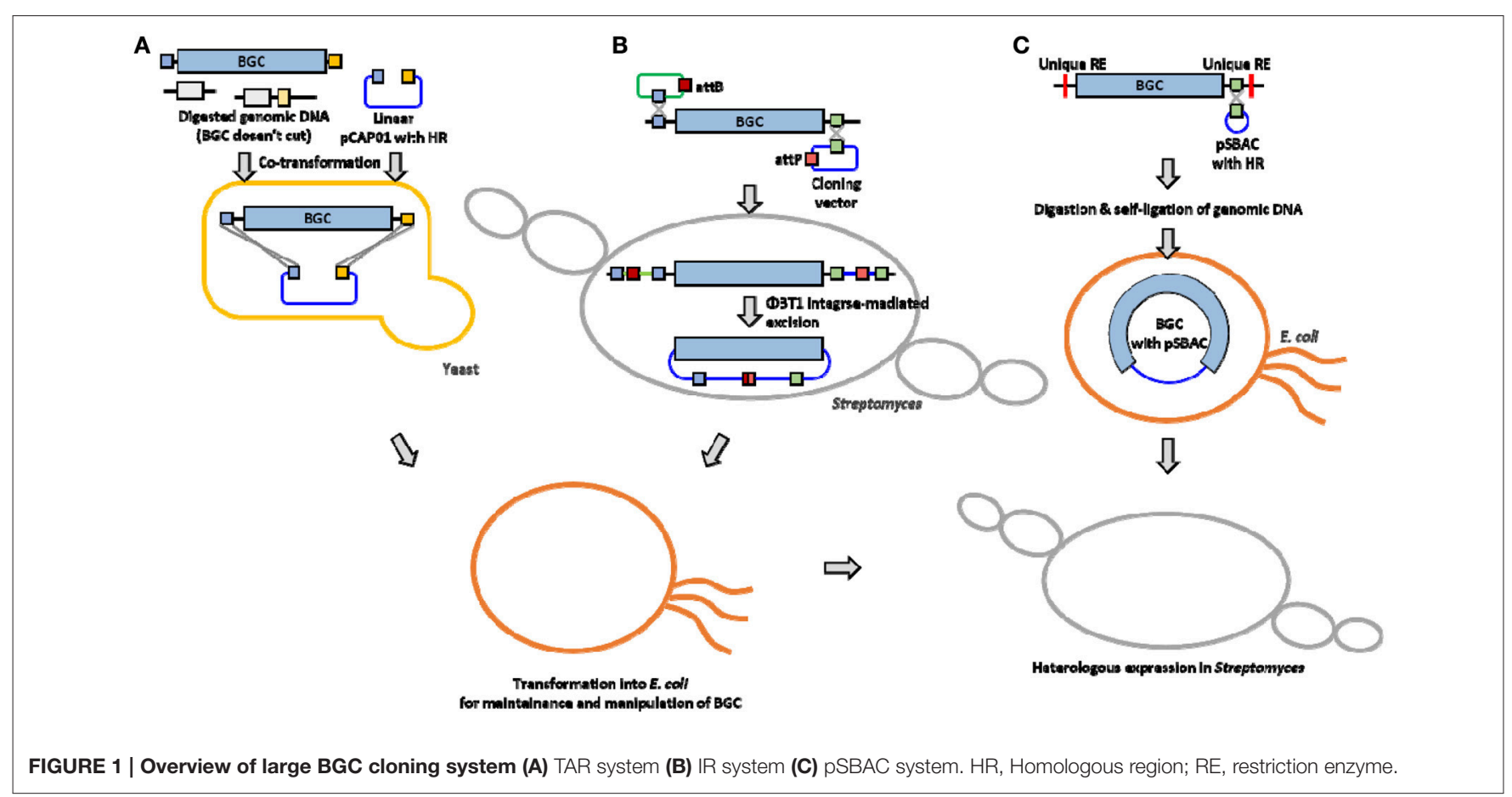

host, but it was presumed to be transferred and maintained by replication in heterologous host (Du et al., 2015).

\section{pSBAC Vector System}

In the early 1990s, Bacterial Artificial Chromosomes (BAC) was reported to carry inserts approaching $200 \mathrm{~kb}$ in length emerged (Shizuya et al., 1992). Various BAC vectors have been used extensively for construction of DNA libraries to facilitate physical genomic mapping and DNA sequencing efforts (Sosio et al., 2000; Martinez et al., 2004; Fuji et al., 2014; Varshney et al., 2014). Several E. coli-Streptomyces shuttle BAC vectors have been developed to carry the large-sized NP BGCs such as pStreptoBAC V and pSBAC (Miao et al., 2005; Liu et al., 2009). The utility of pSBAC was demonstrated through the precise cloning and heterologous expression of the tautomycetin BGC and the pikromycin BGC of the type I PKS biosynthetic pathway, as well as the meridamycin BGC of the PKS-NRPS hybrid biosynthetic pathways (Liu et al., 2009; Nah et al., 2015). Unique restriction enzyme recognition sites naturally existing or artificially inserted into both flanking regions of the entire BGC were used for capturing the BGCs. The pSBAC vector was also inserted within the unique restriction enzyme site by homologous recombination. And then the entire target BGC was captured in a single pSBAC through straightforward single restriction enzyme digestion and self-ligation (Figure 1C). The pSBAC contains two replication origins, ori2 and oriV, for DNA stability in $E$. coli, and oriT and $\Phi C 31$ attP-int for BGC integration into the surrogate host chromosome through intergenic conjugation. The recombinant pSBAC containing the large BGCs of varied length from $40 \mathrm{~kb}$ to over $100 \mathrm{~kb}$ have been successfully cloned and conjugated from E. coli to S. coelicolor and S. lividans (Liu et al., 2009; Nah et al., 2015), implying that the pSBAC system seems to be the most suitable for large BGC cloning comparing with TAR and IR systems.

Recently, a new cloning method named CATCH (Cas9Assisted Targeting of Chromosome) based on the in vitro application of RNA-guided Cas9 nuclease was developed (Jiang and Zhu, 2016). The Cas9 nuclease cleaves target DNA in vitro from intact bacterial chromosomes embedded in agarose plugs, which can be subsequently ligated with cloning vector through Gibson assembly. Jiang and colleagues cloned the $36-\mathrm{kb}$ jadomycin BGC from $S$. venezuelae and the $32-\mathrm{kb}$ chlortetracycline BGC from S. aureofaciens by CATCH (Jiang et al., 2015).

\section{STREPTOMYCES HETEROLOGOUS EXPRESSION OF NP BGCS}

The Streptomyces genus is suitable for heterologous expression of large NP BGCs due to its intrinsic ability to produce various valuable secondary metabolites. Well-studied Streptomyces strains such as $S$. coelicolor, S. lividans, and S. albus have been mainly used as heterologous expression surrogate hosts (Table 1). The regulatory networks of secondary metabolite production have been well characterized in these strains, and thus several NP high-level producing strains have been constructed (Baltz, 2010; Gomez-Escribano and Bibb, 2011). In addition, some of these Streptomyces host genomes have been further engineered to eliminate precursor-competing biosynthetic BGCs, so that the extra precursors such as malonyl-CoA and acetyl-CoA could be funneled into the target polyketide NP biosynthesis (Gomez-Escribano and Bibb, 2011). 
As shown in Table 1, most of the heterologously expressed NPs were detected as a final product, but some were detected as an intermediate due to their partial BGC expression. The NP production yield was similar to or slightly lower than that in WT. To increase the production level in heterologous hosts, it was devised to substitute with strong promoters or to increase the copy number of BGCs (Montiel et al., 2015; Nah et al., 2015). In case of pSBAC system, the tautomycetin production yield in the heterologous hosts was similar to that in the original producing strain. The selection marker on the tautomycetin BGC was changed and re-introduced into the heterologous host by tandem repeat, resulting in further yield increase from 3.05 to $13.31 \mathrm{mg} / \mathrm{L}$ in comparison with the heterologous host harboring only single copy of tautomycetin BGC. The heterologous host harboring tandem copies of tautomycetin BGC was proved to stably maintain two BGCs in the presence of appropriate antibiotic selection (Nah et al., 2015).

Meanwhile, the TAR system used yeast homologous recombination-based promoter engineering for the activation of silent natural product BGCs (Montiel et al., 2015). Bi-directional promoter cassettes were generated by PCR amplification of varied yeast selectable markers, which contains promoterinsulator-RBS combinations, and they were co-transformed with the cosmid or BAC clone harboring the target BGC into yeast. The rebeccamycin BGC was used as a model BGC. The

\section{REFERENCES}

Alexander, D. C., Rock, J., He, X., Brian, P., Miao, V., and Baltz, R. H. (2010). Development of a genetic system for combinatorial biosynthesis of lipopeptides in Streptomyces fradiae and heterologous expression of the A54145 biosynthesis gene cluster. Appl. Environ. Microbiol. 76, 6877-6887. doi: 10.1128/AEM.01248-10

Alt, S., and Wilkinson, B. (2015). Biosynthesis of the novel macrolide antibiotic anthracimycin. ACS Chem. Biol. 10, 2468-2479. doi: 10.1021/acschembio.5b00525

Alvarez-Alvarez, R., Martinez-Burgo, Y., Perez-Redondo, R., Brana, A. F., Martin, J. F., and Liras, P. (2013). Expression of the endogenous and heterologous clavulanic acid cluster in Streptomyces flavogriseus: why a silent cluster is sleeping. Appl. Microbiol. Biotechnol. 97, 9451-9463. doi: 10.1007/s00253-013-5148-7

Baltz, R. H. (2010). Streptomyces and Saccharopolyspora hosts for heterologous expression of secondary metabolite gene clusters. J. Ind. Microbiol. Biotechnol. 37, 759-772. doi: 10.1007/s10295-010-0730-9

Bilyk, O., Sekurova, O. N., Zotchev, S. B., and Luzhetskyy, A. (2016). Cloning and heterologous expression of the grecocycline biosynthetic gene cluster. PLoS ONE 11:e0158682. doi: 10.1371/journal.pone.01 58682

Binnie, C., Warren, M., and Butler, M. J. (1989). Cloning and heterologous expression in Streptomyces lividans of Streptomyces rimosus genes involved in oxytetracycline biosynthesis. J. Bacteriol. 171, 887-895. doi: 10.1128/jb.171.2.887-895.1989

Blodgett, J. A., Zhang, J. K., and Metcalf, W. W. (2005). Molecular cloning, sequence analysis, and heterologous expression of the phosphinothricin tripeptide biosynthetic gene cluster from Streptomyces viridochromogenes DSM 40736. Antimicrob. Agents Chemother. 49, 230-240. doi: 10.1128/AAC.49.1.230-240.2005

Brunker, P., McKinney, K., Sterner, O., Minas, W., and Bailey, J. E. (1999). Isolation and characterization of the naphthocyclinone gene cluster from Streptomyces arenae DSM 40737 and heterologous expression of the polyketide synthase genes. Gene 227, 125-135. doi: 10.1016/S0378-1119(98)00618-0 promoter-replaced rebeccamycin BGC was transferred into $S$. albus by conjugation, and the production of rebeccamycin was examined in the heterologous host (Montiel et al., 2015). Using the TAR-based promoter engineering strategy, multiple promoter cassettes could be inserted simultaneously into the target BGC, thereby expediting the re-engineering process. The TAR-based promoter engineering strategy was also used to capture the silent tetarimycin BGC and the silent, cryptic pseudogene-containing, environmental DNA-derived lazarimide BGC (Montiel et al., 2015).

In conclusion, Streptomyces heterologous expression systems have been proved to be a very attractive strategy to awaken cryptic NP BGCs, and could also be applied to overexpression of a variety of large NP BGCs in actinomycetes.

\section{AUTHOR CONTRIBUTIONS}

HN, SK, SC, and EK planned, outlined, and revised the manuscript. HN, HP, and EK wrote and revised the manuscript.

\section{ACKNOWLEDGMENTS}

This research was supported by "National Research Foundation of Korea (NRF)” (Project No. NRF-2014R1A2A1A11052236 \& NRF-2016K2A9A2A10005545).
Cano-Prieto, C., Garcia-Salcedo, R., Sanchez-Hidalgo, M., Brana, A. F., Fiedler, H. P., Mendez, C., et al. (2015). Genome mining of Streptomyces sp. Tu 6176: characterization of the nataxazole biosynthesis pathway. Chembiochem 16, 1461-1473. doi: 10.1002/cbic.201500153

Castro, J. F., Razmilic, V., Gomez-Escribano, J. P., Andrews, B., Asenjo, J. A., and Bibb, M. J. (2015). Identification and heterologous expression of the chaxamycin biosynthesis gene cluster from Streptomyces leeuwenhoekii. Appl. Environ. Microbiol. 81, 5820-5831. doi: 10.1128/AEM.01039-15

Chen, C., Zhao, X., Jin, Y., Zhao, Z. K., and Suh, J. W. (2014). Rapid construction of a bacterial artificial chromosomal (BAC) expression vector using designer DNA fragments. Plasmid 76, 79-86. doi: 10.1016/j.plasmid.2014. 10.002

Chen, W., and Qin, Z. (2011). Development of a gene cloning system in a fast-growing and moderately thermophilic Streptomyces species and heterologous expression of Streptomyces antibiotic biosynthetic gene clusters. BMC Microbiol. 11:243. doi: 10.1186/1471-2180-11-243

Cone, M. C., Yin, X., Grochowski, L. L., Parker, M. R. and Zabriskie, T. M. (2003). The blasticidin S biosynthesis gene cluster from Streptomyces griseochromogenes: sequence analysis, organization, and initial characterization. ChemBioChem 4, 821-828. doi: 10.1002/cbic.200 300583

Donadio, S., Monciardini, P., and Sosio, M. (2007). Polyketide synthases and nonribosomal peptide synthetases: the emerging view from bacterial genomics. Nat. Prod. Rep. 24, 1073-1109. doi: 10.1039/b514050c

Du, D., Wang, L., Tian, Y., Liu, H., Tan, H., and Niu, G. (2015). Genome engineering and direct cloning of antibiotic gene clusters via phage $\Phi B T 1$ integrase-mediated site-specific recombination in Streptomyces. Sci. Rep. 5:8740. doi: $10.1038 /$ srep08740

Engelhardt, K., Degnes, K. F., and Zotchev, S. B. (2010). Isolation and characterization of the gene cluster for biosynthesis of the thiopeptide antibiotic TP-1161. Appl. Environ. Microbiol. 76, 7093-7101. doi: 10.1128/AEM.01442-10

Feng, Z., Kim, J. H., and Brady, S. F. (2010). Fluostatins produced by the heterologous expression of a TAR reassembled environmental DNA derived type II PKS gene cluster. J. Am. Chem. Soc. 132, 11902-11903. doi: 10.1021/ja104550p 
Fischer, C., Lipata, F., and Rohr, J. (2003). The complete gene cluster of the antitumor agent gilvocarcin $\mathrm{V}$ and its implication for the biosynthesis of the gilvocarcins. J. Am. Chem. Soc. 125, 7818-7819. doi: 10.1021/ja034781q

Flinspach, K., Kapitzke, C., Tocchetti, A., Sosio, M., and Apel, A. K. (2014). Heterologous expression of the thiopeptide antibiotic GE2270 from Planobispora rosea ATCC 53733 in Streptomyces coelicolor requires deletion of ribosomal genes from the expression construct. PLoS ONE 9:e90499. doi: 10.1371/journal.pone.0090499

Fuji, K., Koyama, T., Kai, W., Kubota, S., Yoshida, K., Ozaki, A., et al. (2014). Construction of a high-coverage bacterial artificial chromosome library and comprehensive genetic linkage map of yellowtail Seriola quinqueradiata. BMC Res. Notes 7:200. doi: 10.1186/1756-0500-7-200

Galm, U., and Shen, B. (2006). Expression of biosynthetic gene clusters in heterologous hosts for natural product production and combinatorial biosynthesis. Expert Opin. Drug Discov. 1, 409-437. doi: 10.1517/17460441.1.5.409

Gomez-Escribano, J. P., and Bibb, M. J. (2011). Engineering Streptomyces coelicolor for heterologous expression of secondary metabolite gene clusters. Microb. Biotechnol. 4, 207-215. doi: 10.1111/j.1751-7915.2010.00219.x

Gould, S. J., Hong, S. T., and Carney, J. R. (1998). Cloning and heterologous expression of genes from the kinamycin biosynthetic pathway of Streptomyces murayamaensis. J. Antibiot. (Tokyo) 51, 50-57. doi: 10.7164/antibiotics.51.50

Haginaka, K., Asamizu, S., Ozaki, T., Igarashi, Y., Furumai, T., and Onaka, H. (2014). Genetic approaches to generate hyper-producing strains of goadsporin: the relationships between productivity and gene duplication in secondary metabolite biosynthesis. Biosci. Biotechnol. Biochem. 78, 394-399. doi: 10.1080/09168451.2014.885824

Hashimoto, T., Hashimoto, J., Teruya, K., Hirano, T., Shin-ya, K., Ikeda, H., et al. (2015). Biosynthesis of versipelostatin: identification of an enzymecatalyzed [4+2]-cycloaddition required for macrocyclization of spirotetronatecontaining polyketides. J. Am. Chem. Soc. 137, 572-575. doi: 10.1021/ja51 $0711 \mathrm{x}$

He, J., and Hertweck, C. (2003). Iteration as programmed event during polyketide assembly; molecular analysis of the aureothin biosynthesis gene cluster. Chem. Biol. 10, 1225-1232. doi: 10.1016/j.chembiol.2003.11.009

Hong, S. T., Carney, J. R., and Gould, S. J. (1997). Cloning and heterologous expression of the entire gene clusters for PD 116740 from Streptomyces strain WP 4669 and tetrangulol and tetrangomycin from Streptomyces rimosus NRRL 3016. J Bacteriol. 179, 470-476. doi: 10.1128/jb.179.2.470-476.1997

Ichinose, K., Bedford, D. J., Tornus, D., Bechthold, A., Bibb, M. J., Revill, W. P., et al. (1998). The granaticin biosynthetic gene cluster of Streptomyces violaceoruber Tu22: sequence analysis and expression in a heterologous host. Chem. Biol. 5, 647-659. doi: 10.1016/S1074-5521(98)90292-7

Ichinose, K., Ozawa, M., Itou, K., Kunieda, K., and Ebizuka, Y. (2003). Cloning, sequencing and heterologous expression of the medermycin biosynthetic gene cluster of Streptomyces sp. AM-7161: towards comparative analysis of the benzoisochromanequinone gene clusters. Microbiology 149, 1633-1645. doi: $10.1099 /$ mic. $0.26310-0$

Iftime, D., Jasyk, M., Kulik, A., Imhoff, J. F., Stegmann, E., Wohlleben, W., et al. (2015). Streptocollin, a Type IV lanthipeptide produced by Streptomyces collinus $\mathrm{Tu}$ 365. Chembiochem 16, 2615-2623. doi: 10.1002/cbic.2015 00377

Izawa, M., Kawasaki, T., and Hayakawa, Y. (2013). Cloning and heterologous expression of the thioviridamide biosynthesis gene cluster from Streptomyces olivoviridis. Appl. Environ. Microbiol. 79, 7110-7113. doi: 10.1128/AEM.01978-13

Izumikawa, M., Kozone, I., Hashimoto, J., Kagaya, N., Takagi, M., Koiwai, H., et al. (2015). Novel thioviridamide derivative-JBIR-140: heterologous expression of the gene cluster for thioviridamide biosynthesis. J. Antibiot. (Tokyo) 68, 533-536. doi: 10.1038/ja.2015.20

Jian, X. H., Pan, H. X., Ning, T. T., Shi, Y. Y., Chen, Y. S., Li, Y., et al. (2012). Analysis of YM-216391 biosynthetic gene cluster and improvement of the cyclopeptide production in a heterologous host. ACS Chem. Biol. 7, 646-651. doi: $10.1021 / \mathrm{cb} 200479 \mathrm{f}$

Jiang, W., Zhao, X., Gabrieli, T., Lou, C., Ebenstein, Y., and Zhu, T. F. (2015). Cas9assisted targeting of chromosome segments $\mathrm{CATCH}$ enables one-step targeted cloning of large gene clusters. Nat. Commun. 6:9101. doi: 10.1038/ncomms9101
Jiang, W., and Zhu, T. F. (2016). Targeted isolation and cloning of 100-kb microbial genomic sequences by Cas9-assisted targeting of chromosome segments. Nat. Protoc. 11, 960-975. doi: 10.1038/nprot.2016.055

Jones, A. C., Gust, B., Kulik, A., Heide, L., Buttner, M. J., and Bibb, M. J. (2013). Phage p1-derived artificial chromosomes facilitate heterologous expression of the FK506 gene cluster. PLoS ONE 8:e69319. doi: 10.1371/journal.pone.0069319

Jones, A. C., Ottilie, S., Eustaquio, A. S., Edwards, D. J., Gerwick, L., Moore, B. S., et al. (2012). Evaluation of Streptomyces coelicolor A3(2) as a heterologous expression host for the cyanobacterial protein kinase $\mathrm{C}$ activator lyngbyatoxin A. FEBS J. 279, 1243-1251. doi: 10.1111/j.1742-4658.2012.08517.x

Jordan, P. A., and Moore, B. S. (2016). Biosynthetic pathway connects cryptic ribosomally synthesized posttranslationally modified peptide genes with pyrroloquinoline alkaloids. Cell Chem. Biol. 23, 1504-1514. doi: 10.1016/j.chembiol.2016.10.009

Kaysser, L., Bernhardt, P., Nam, S. J., Loesgen, S., Ruby, J. G., Skewes-Cox, P., et al. (2012). Merochlorins, A.-D., cyclic meroterpenoid antibiotics biosynthesized in divergent pathways with vanadium-dependent chloroperoxidases. J. Am. Chem. Soc. 134, 11988-11991. doi: 10.1021/ja305665f

Kharel, M. K., Nybo, S. E., Shepherd, M. D., and Rohr, J. (2010). Cloning and characterization of the ravidomycin and chrysomycin biosynthetic gene clusters. Chembiochem 11, 523-532. doi: 10.1002/cbic.200900673

Kim, E. J., Lee, J. H., Choi, H., Pereira, A. R., Ban, Y. H., Yoo, Y. J., et al. (2012). Heterologous production of 4-O-demethylbarbamide, a marine cyanobacterial natural product. Org. Lett. 14, 5824-5827. doi: 10.1021/ol302575h

Kim, J. H., Feng, Z., Bauer, J. D., Kallifidas, D., Calle, P. Y., and Brady, S. F. (2010). Cloning large natural product gene clusters from the environment: piecing environmental DNA gene clusters back together with TAR. Biopolymers 93, 833-844. doi: 10.1002/bip.21450

Koberska, M., Kopecky, J., Olsovska, J., Jelinkova, M., Ulanova, D., Man, P., et al. (2008). Sequence analysis and heterologous expression of the lincomycin biosynthetic cluster of the type strain Streptomyces lincolnensis ATCC 25466. Folia Microbiol. (Praha) 53, 395-401. doi: 10.1007/s12223-008-0060-8

Kudo, F., Tsunoda, T., Takashima, M., and Eguchi, T. (2016). Five-membered cyclitol phosphate formation by a myo-inositol phosphate synthase orthologue in the biosynthesis of the carbocyclic nucleoside antibiotic aristeromycin. Chembiochem 17, 2143-2148. doi: 10.1002/cbic.201600348

Kwon, H. J., Smith, W. C., Xiang, L., and Shen, B. (2001). Cloning and heterologous expression of the macrotetrolide biosynthetic gene cluster revealed a novel polyketide synthase that lacks an acyl carrier protein. J. Am. Chem. Soc. 123, 3385-3386. doi: 10.1021/ja0100827

Lacalle, R. A., Tercero, J. A., and Jimenez, A. (1992). Cloning of the complete biosynthetic gene cluster for an aminonucleoside antibiotic, puromycin, and its regulated expression in heterologous hosts. EMBO J. 11, 785-792.

Larionov, V., Kouprina, N., Eldarov, M., Perkins, E., Porter, G., and Resnick, M. A. (1994). Transformation-associated recombination between diverged and homologous DNA repeats is induced by strand breaks. Yeast 10, 93-104. doi: 10.1002/yea.320100109

Li, J., Guo, Z., Huang, W., Meng, X., Ai, G., Tang, G., et al. (2013). Mining of a streptothricin gene cluster from Streptomyces sp. TP-A0356 genome via heterologous expression. Sci. China Life Sci. 56, 619-627. doi: 10.1007/s11427-013-4504-2

Li, Q., Song, Y., Qin, X., Zhang, X., Sun, A., and Ju, J. (2015). Identification of the biosynthetic gene cluster for the anti-infective desotamides and production of a new analogue in a heterologous host. J. Nat. Prod. 78, 944-948. doi: 10.1021/acs.jnatprod.5b00009

Li, T., Du, Y., Cui, Q., Zhang, J., Zhu, W., Hong, K., et al. (2013). Cloning, characterization and heterologous expression of the indolocarbazole biosynthetic gene cluster from marine-derived Streptomyces sanyensis FMA. Mar. Drugs 11, 466-488. doi: 10.3390/md11020466

Liu, C., Zhang, J., Lu, C., and Shen, Y. (2015). Heterologous expression of galbonolide biosynthetic genes in Streptomyces coelicolor. Antonie Van Leeuwenhoek 107, 1359-1366. doi: 10.1007/s10482-015-0415-5

Liu, H., Jiang, H., Haltli, B., Kulowski, K., Muszynska, E., Feng, X., et al. (2009). Rapid cloning and heterologous expression of the meridamycin biosynthetic gene cluster using a versatile Escherichia coli-Streptomyces artificial chromosome vector, pSBAC. J. Nat. Prod. 72, 389-395. doi: 10.1021/np8006149 
Lopez, P., Hornung, A., Welzel, K., Unsin, C., Wohlleben, W., Weber, T., et al. (2010). Isolation of the lysolipin gene cluster of Streptomyces tendae Tu. Gene 461, 5-14. doi: 10.1016/j.gene.2010.03.016

Malcolmson, S. J., Young, T. S., Ruby, J. G., Skewes-Cox, P., and Walsh, C. T. (2013). The posttranslational modification cascade to the thiopeptide berninamycin generates linear forms and altered macrocyclic scaffolds. Proc. Natl. Acad. Sci. U.S.A. 110, 8483-8488. doi: 10.1073/pnas.1307111110

Malpartida, F., Niemi, J., Navarrete, R., and Hopwood, D. A. (1990). Cloning and expression in a heterologous host of the complete set of genes for biosynthesis of the Streptomyces coelicolor antibiotic undecylprodigiosin. Gene 93, 91-99. doi: 10.1016/0378-1119(90)90141-D

Mantovani, S. M., and Moore, B. S. (2013). Flavin-linked oxidase catalyzes pyrrolizine formation of dichloropyrrole-containing polyketide extender unit in chlorizidine A. J. Am. Chem. Soc. 135, 18032-18035. doi: 10.1021/ja409520v

Marti, T., Hu, Z., Pohl, N. L., Shah, A. N., and Khosla, C. (2000). Cloning, nucleotide sequence, and heterologous expression of the biosynthetic gene cluster for R1128, a non-steroidal estrogen receptor antagonist. Insights into an unusual priming mechanism. J. Biol. Chem. 275, 33443-33448. doi: 10.1074/jbc.M006766200

Martinez, A., Kolvek, S. J., Tiong Yip, C. L., Hopke, J., Brown, K. A., MacNeil, I. A., et al. (2004). Genetically modified bacterial strains and novel bacterial artificial chromosome shuttle vectors for constructing environmental libraries and detecting heterologous natural products in multiple expression hosts. Appl. Environ. Microbiol. 70, 2452-2463. doi: 10.1128/AEM.70.4.2452-2463.2004

Martinez-Burgo, Y., Alvarez-Alvarez, R., Perez-Redondo, R., and Liras, P. (2014). Heterologous expression of Streptomyces clavuligerus ATCC 27064 cephamycin C gene cluster. J. Biotechnol. 186, 21-29. doi: 10.1016/j.jbiotec.2014.06.002

McClure, R. A., Goering, A. W., Ju, K. S., Baccile, J. A., Schroeder, F. C., Metcalf, W. W., et al. (2016). Elucidating the rimosamide-detoxin natural product families and their biosynthesis using metabolite/gene cluster correlations. ACS Chem. Biol. 11, 3452-3460. doi: 10.1021/acschembio.6b00779

Miao, V., Coeffet-LeGal, M., Brian, P., Brost, R., Penn, J., Whiting, A., et al. (2005). Daptomycin biosynthesis in Streptomyces roseosporus: cloning and analysis of the gene cluster and revision of peptide stereochemistry. Microbiology $151(\mathrm{Pt}$ 5), 1507-1523. doi: 10.1099/mic.0.27757-0

Miyamoto, K. T., Komatsu, M., and Ikeda, H. (2014). Discovery of gene cluster for mycosporine-like amino acid biosynthesis from Actinomycetales microorganisms and production of a novel mycosporine-like amino acid by heterologous expression. Appl. Environ. Microbiol. 80, 5028-5036. doi: 10.1128/AEM.00727-14

Montiel, D., Kang, H. S., Chang, F. Y., Charlop-Powers, Z., and Brady, S. F. (2015). Yeast homologous recombination-based promoter engineering for the activation of silent natural product biosynthetic gene clusters. Proc. Natl. Acad. Sci. U.S.A. 112, 8953-8958. doi: 10.1073/pnas.1507606112

Motamedi, H., and Hutchinson, C. R. (1987). Cloning and heterologous expression of a gene cluster for the biosynthesis of tetracenomycin $\mathrm{C}$, the anthracycline antitumor antibiotic of Streptomyces glaucescens. Proc. Natl. Acad. Sci. U.S.A. 84, 4445-4449. doi: 10.1073/pnas.84.13.4445

Nah, H. J., Woo, M. W., Choi, S. S., and Kim, E. S. (2015). Precise cloning and tandem integration of large polyketide biosynthetic gene cluster using Streptomyces artificial chromosome system. Microb. Cell Fact. 14, 140. doi: 10.1186/s12934-015-0325-2

Newman, D. J., and Cragg, G. M. (2012). Natural products as sources of new drugs over the 30 years from 1981 to 2010. J. Nat. Prod. 75, 311-335. doi: $10.1021 / \mathrm{np} 200906 \mathrm{~s}$

Niu, G., Li, L., Wei, J., and Tan, H. (2013). Cloning, heterologous expression, and characterization of the gene cluster required for gougerotin biosynthesis. Chem. Biol. 20, 34-44. doi: 10.1016/j.chembiol.2012.10.017

Onaka, H., Taniguchi, S., Igarashi, Y., and Furumai, T. (2002). Cloning of the staurosporine biosynthetic gene cluster from Streptomyces sp. TP-A0274 and its heterologous expression in Streptomyces lividans. J. Antibiot. (Tokyo) 55, 1063-10671. doi: 10.7164/antibiotics.55.1063

Ooya, K., Ogasawara, Y., Noike, M., and Dairi, T. (2015). Identification and analysis of the resorcinomycin biosynthetic gene cluster. Biosci. Biotechnol. Biochem. 79, 1833-1837. doi: 10.1080/09168451.2015.1050992

Otsuka, M., Ichinose, K., Fujii, I., and Ebizuka, Y. (2004). Cloning, sequencing, and functional analysis of an iterative type I polyketide synthase gene cluster for biosynthesis of the antitumor chlorinated polyenone neocarzilin in
"Streptomyces carzinostaticus." Antimicrob. Agents Chemother. 48, 3468-3476. doi: 10.1128/AAC.48.9.3468-3476.2004

Park, O. K., Choi, H. Y., Kim, G. W., and Kim, W. G. (2016). Generation of new complestatin analogues by heterologous expression of the complestatin biosynthetic gene cluster from Streptomyces chartreusis AN1542. Chembiochem 17, 1725-1731. doi: 10.1002/cbic.201600241

Robles-Reglero, V., Santamarta, I., Alvarez-Alvarez, R., Martin, J. F., and Liras, P. (2013). Transcriptional analysis and proteomics of the holomycin gene cluster in overproducer mutants of Streptomyces clavuligerus. J. Biotechnol. 163, 69-76. doi: 10.1016/j.jbiotec.2012.09.017

Rui, Z., Huang, W., Xu, F., Han, M., Liu, X., Lin, S., et al. (2015). Sparsomycin biosynthesis highlights unusual module architecture and processing mechanism in non-ribosomal peptide synthetase. ACS Chem. Biol. 10, 1765-1769. doi: 10.1021/acschembio.5b00284

Salem, S. M., Kancharla, P., Florova, G., Gupta, S., Lu, W., and Reynolds, K. A. (2014). Elucidation of final steps of the marineosins biosynthetic pathway through identification and characterization of the corresponding gene cluster. J. Am. Chem. Soc. 136, 4565-4574. doi: 10.1021/ja411544w

Sanchez, C., Butovich, I. A., Brana, A. F., Rohr, J., Mendez, C., and Salas, J. A. (2002). The biosynthetic gene cluster for the antitumor rebeccamycin: characterization and generation of indolocarbazole derivatives. Chem. Biol. 9, 519-531. doi: 10.1016/S1074-5521(02)00126-6

Saugar, I., Molloy, B., Sanz, E., Blanca Sanchez, M., Fernandez-Lobato, M., and Jimenez, A. (2016). Characterization of the biosynthetic gene cluster (ata) for the A201A aminonucleoside antibiotic from Saccharothrix mutabilis subsp. capreolus. J. Antibiot. (Tokyo). doi: 10.1038/ja.2016.123. [Epub ahead of print].

Shah, S., Xue, Q., Tang, L., Carney, J. R., Betlach, M., and McDaniel, R. (2000). Cloning, characterization and heterologous expression of a polyketide synthase and P-450 oxidase involved in the biosynthesis of the antibiotic oleandomycin. J. Antibiot. (Tokyo) 53, 502-508. doi: 10.7164/antibiotics.53.502

Shizuya, H., Birren, B., Kim, U. J., Mancino, V., Slepak, T., Tachiiri, Y., et al. (1992). Cloning and stable maintenance of 300-kilobase-pair fragments of human DNA in Escherichia coli using an F-factor-based vector. Proc. Natl. Acad. Sci. U.S.A. 89, 8794-8797. doi: 10.1073/pnas.89.18.8794

Singh, D., Seo, M. J., Kwon, H. J., Rajkarnikar, A., Kim, K. R., Kim, S. O., et al. (2006). Genetic localization and heterologous expression of validamycin biosynthetic gene cluster isolated from Streptomyces hygroscopicus var. limoneus KCCM 11405 (IFO 12704). Gene 376, 13-23. doi: $10.1016 /$ j.gene.2005.12.035

Sosio, M., Giusino, F., Cappellano, C., Bossi, E., Puglia, A. M., and Donadio, S. (2000). Artificial chromosomes for antibiotic-producing actinomycetes. Nat. Biotechnol. 18, 343-345. doi: 10.1038/73810

Steffensky, M., Muhlenweg, A., Wang, Z. X., Li, S. M., and Heide, L. (2000). Identification of the novobiocin biosynthetic gene cluster of Streptomyces spheroides NCIB 11891. Antimicrob. Agents Chemother. 44, 1214-1222. doi: 10.1128/AAC.44.5.1214-1222.2000

Su, C., Zhao, X., Qiu, R., and Tang, L. (2015). Construction of the co-expression plasmids of fostriecin polyketide synthases and heterologous expression in Streptomyces. Pharm. Biol. 53, 269-274. doi: 10.3109/13880209.2014.914956

Tang, L., Shah, S., Chung, L., Carney, J., Katz, L., Khosla, C., et al. (2000). Cloning and heterologous expression of the epothilone gene cluster. Science 287, 640-642. doi: 10.1126/science.287.5453.640

Thanapipatsiri, A., Gomez-Escribano, J. P., Song, L., Bibb, M. J., Al-Bassam, M., Chandra, G., et al. (2016). Discovery of unusual biaryl polyketides by activation of a silent Streptomyces venezuelae biosynthetic gene cluster. Chembiochem 17, 2189-2198. doi: 10.1002/cbic.201600396

Thapa, L. P., Oh, T. J., Lee, H. C., Liou, K., Park, J. W., Yoon, Y. J., et al. (2007). Heterologous expression of the kanamycin biosynthetic gene cluster (pSKC2) in Streptomyces venezuelae YJ003. Appl. Microbiol. Biotechnol. 76, 1357-1364. doi: 10.1007/s00253-007-1096-4

Torkkell, S., Kunnari, T., Palmu, K., Mantsala, P., Hakala, J., and Ylihonko, K. (2001). The entire nogalamycin biosynthetic gene cluster of Streptomyces nogalater: characterization of a 20-kb DNA region and generation of hybrid structures. Mol. Genet. Genomics 266, 276-288. doi: 10.1007/s0043801 00554

Varshney, R. K., Mir, R. R., Bhatia, S., Thudi, M., Hu, Y., Azam, S., et al. (2014). Integrated physical, genetic and genome map of chickpea (Cicer arietinum L.). Funct. Integr. Genomics 14, 59-73. doi: 10.1007/s10142-014-0363-6 
Waldman, A. J., Pechersky, Y., Wang, P., Wang, J. X., and Balskus, E. P. (2015). The cremeomycin biosynthetic gene cluster encodes a pathway for diazo formation. Chembiochem 16, 2172-2175. doi: 10.1002/cbic.201 500407

Wang, J., Yu, Y., Tang, K., Liu, W., He, X., Huang, X., et al. (2010). Identification and analysis of the biosynthetic gene cluster encoding the thiopeptide antibiotic cyclothiazomycin in Streptomyces hygroscopicus 10-22. Appl. Environ. Microbiol. 76, 2335-2344. doi: 10.1128/AEM.01 790-09

Ward, S. L., Hu, Z., Schirmer, A., Reid, R., Revill, W. P., Reeves, C. D., et al. (2004). Chalcomycin biosynthesis gene cluster from Streptomyces bikiniensis: novel features of an unusual ketolide produced through expression of the chm polyketide synthase in Streptomyces fradiae. Antimicrob. Agents Chemother. 48, 4703-4712. doi: 10.1128/AAC.48.12.4703-4712.2004

Wolpert, M., Heide, L., Kammerer, B., and Gust, B. (2008). Assembly and heterologous expression of the coumermycin Al gene cluster and production of new derivatives by genetic engineering. Chembiochem 9, 603-612. doi: 10.1002/cbic. 200700483

Yamanaka, K., Reynolds, K. A., Kersten, R. D., Ryan, K. S., Gonzalez, D. J., Nizet, V., et al. (2014). Direct cloning and refactoring of a silent lipopeptide biosynthetic gene cluster yields the antibiotic taromycin A. Proc. Natl. Acad. Sci. U.S.A. 111, 1957-1962. doi: 10.1073/pnas.1319584111

Yan, X., Probst, K., Linnenbrink, A., Arnold, M., Paululat, T., Zeeck, A., et al. (2012). Cloning and heterologous expression of three type II PKS gene clusters from Streptomyces bottropensis. Chembiochem 13, 224-230. doi: 10.1002/cbic.201100574

Yang, C., Huang, C., Zhang, W., Zhu, Y., and Zhang, C. (2015). Heterologous expression of fluostatin gene cluster leads to a bioactive heterodimer. Org. Lett. 17, 5324-5327. doi: 10.1021/acs.orglett.5b02683

Yin, J., Hoffmann, M., Bian, X., Tu, Q., Yan, F., Xia, L., et al. (2015). Direct cloning and heterologous expression of the salinomycin biosynthetic gene cluster from Streptomyces albus DSM41398 in Streptomyces coelicolor A3(2). Sci. Rep. 5:15081. doi: 10.1038/srep15081

Yin, S., Li, Z., Wang, X., Wang, H., Jia, X., Ai, G., et al. (2016). Heterologous expression of oxytetracycline biosynthetic gene cluster in Streptomyces venezuelae WVR2006 to improve production level and to alter fermentation process. Appl. Microbiol. Biotechnol. 100, 10563-10572. doi: 10.1007/s00253-016-7873-1
Ylihonko, K., Hakala, J., Kunnari, T., and Mantsala, P. (1996). Production of hybrid anthracycline antibiotics by heterologous expression of Streptomyces nogalater nogalamycin biosynthesis genes. Microbiology 142(Pt 8), 1965-1972. doi: 10.1099/13500872-142-8-1965

Young, T. S., and Walsh, C. T. (2011). Identification of the thiazolyl peptide GE37468 gene cluster from Streptomyces ATCC 55365 and heterologous expression in Streptomyces lividans. Proc. Natl. Acad. Sci. U.S.A. 108, 13053-13058. doi: 10.1073/pnas.1110435108

Zaburannyi, N., Rabyk, M., Ostash, B., Fedorenko, V., and Luzhetskyy, A. (2014). Insights into naturally minimised Streptomyces albus J1074 genome. BMC Genomics 15:97. doi: 10.1186/1471-2164-15-97

Zettler, J., Xia, H., Burkard, N., Kulik, A., Grond, S., Heide, L., et al. (2014). New aminocoumarins from the rare actinomycete Catenulispora acidiphila DSM 44928: identification, structure elucidation, and heterologous production. Chembiochem 15, 612-621. doi: 10.1002/cbic.201300712

Zhang, G., Zhang, H., Li, S., Xiao, J., Zhang, G., Zhu, Y., et al. (2012). Characterization of the amicetin biosynthesis gene cluster from Streptomyces vinaceusdrappus NRRL 2363 implicates two alternative strategies for amide bond formation. Appl. Environ. Microbiol. 78, 2393-2401. doi: 10.1128/AEM.07185-11

Zhang, Y., Huang, H., Chen, Q., Luo, M., Sun, A., Song, Y., et al. (2013). Identification of the grincamycin gene cluster unveils divergent roles for GcnQ in different hosts, tailoring the L-rhodinose moiety. Org. Lett. 15, 3254-3257. doi: 10.1021/ol401253p

Zhu, Y., Fu, P., Lin, Q., Zhang, G., Zhang, H., Li, S., et al. (2012). Identification of caerulomycin A gene cluster implicates a tailoring amidohydrolase. Org. Lett. 14, 2666-2669. doi: 10.1021/ol300589r

Conflict of Interest Statement: The authors declare that the research was conducted in the absence of any commercial or financial relationships that could be construed as a potential conflict of interest.

Copyright (c) 2017 Nah, Pyeon, Kang, Choi and Kim. This is an open-access article distributed under the terms of the Creative Commons Attribution License (CC BY). The use, distribution or reproduction in other forums is permitted, provided the original author(s) or licensor are credited and that the original publication in this journal is cited, in accordance with accepted academic practice. No use, distribution or reproduction is permitted which does not comply with these terms. 